\title{
Discussion on the Direction of Undergraduate Electro-Mechanical Integration for Local Economy
}

\author{
Yi Jiangang ${ }^{1}$ \\ School of Electromechanical and Architectural Engineering \\ Jianghan University \\ Wuhan, China \\ E-mail address: yjg_wh@yeah.net
}

\author{
Ju Siwei ${ }^{2}$ \\ School of Electromechanical and Architectural Engineering \\ Jianghan University \\ Wuhan, China \\ E-mail address: 598391324@qq.com
}

\begin{abstract}
The direction of electro-mechanical integration in advanced education is a comprehensive major direction which includes the collection of machines, electricity, automatic control and detection, computer applications and other disciplines. The direction of major orientation was determined, general knowledge, subject foundation, specialty, practice and quality development was developed, the research of teaching reform and methods, improving teaching staff structure was put forward according to the general requirements, comprehensive local economic construction and social development planning and analysis of the professional training requirements and plans, the training system of innovative talents in the direction of electromechanical major was constructed by enhancing its overall quality and the construction of subject echelon and other specific measures, which meet the requirements of the times, the local economic construction and social development for talents.
\end{abstract}

Keywords-Electro-mechanical integration; Talent training; Advanced education; Local economy

\section{INTRODUCTION}

The direction of electro-mechanical integration in undergraduate education is a comprehensive professional based on the integration of machine, electricity, automatic control and detection and computer application, the main courses are mechanical drawing, theoretical mechanics, mechanics of materials, mechanical principle, mechanical design, circuit theory, analog electronics, digital electronics mechanical engineering technology, control foundation, metal material and heat treatment, interchangeability and measuring technology, testing technology and signal analysis, machinery manufacturing base, laser principle and manufacturing technology, hydraulic transmission, numerical control technology [1-4]. The main purpose of the direction is to train the engineering technical talents of electro-mechanics [5]. The undergraduates are supposed to be able to develop and apply hardware and software in electronic technology and microcomputer (including the MCU) strongly, and do innovation and creation of miniature intelligent products independently with basic knowledge and necessary skills of machine, electricity, computer etc. The technical personnel of direction is one of the ten most urgent talents for the social development in twenty-first Century. Therefore, constructing the electromechanical integration direction well is of great practical significance.

\section{ORIENTATION OF MAJOR CONSTRUCTION}

Adhere to the policy of "development, reform, consolidate and improve" and people-oriented, promote the innovation of system, mechanism, the transformation of the mode of development in advanced education, and make the professional direction bigger and stronger, enhance the function of the construction of advanced education to serve the local economy and the social development further according to the general requirements of local economic construction and social development plan. Combined with the requirements of regional economic development closely, strengthen the cooperation of school and enterprise, take full use of enterprise resources based on the existing school discipline and professional advantages, take full advantages of school and enterprise, establish school-enterprise joint teaching and research system. invite cooperation enterprises and scientific research institutes of high level technical personnel to participate in the teaching work and formulate development planning, implementation of the school enterprise win-win jointly according to the professional characteristics in the dual core of school classroom and extracurricular practice, of which the structure of school enterprise joint center is shown in figure 1. At the same time, take the development road of connotation construction, improve the quality of education and teaching steadily, and highlight the applied characteristics of engineering disciplines according to the situation of social talent demand and conditions [6].

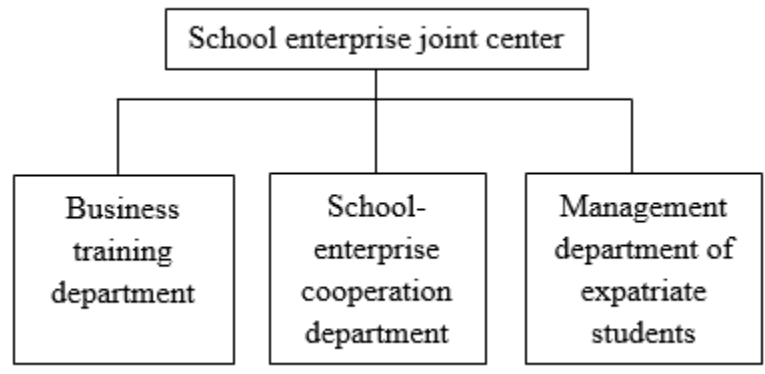

Fig. 1 Structure diagram of school enterprise joint center 


\section{TALENT TRAINING REQUIREMENTS}

Based on current " $3+1$ ", "dual system" training mode, strengthen the cultivation of students' ability of comprehension and innovation, construct of diversified practical teaching mode of students' personality development, and explore the teaching and experiment of curriculum reform actively, optimize the current structure of curriculum system constantly, cultivating innovative talents that enterprises really require in the direction of the inherent law and market demand. Of which the requirements of direction of training talents are the followings: the undergraduates are supposed to learn the basic theory of mechanical design and manufacturing, the basic knowledge of electrical and electronic technology, computer technology and control technology, master the modern design method, basic training of modern mechanical engineers, be able to design mechanical products, electromechanical product and manufacture, control, organize and manage the equipment. Training the undergraduates to apply and research in mechatronics with the professional ability to engage in the design, manufacture, test and computer application in electro-mechanical products.

The graduates are supposed to acquire the following knowledge and ability:

(1) A solid foundation of natural science, a good foundation of humanities, art and social science, and using their own language and writing ability right;

(2)Mastering the theoretical basis of this major systematically, including basic knowledge of mechanics, electrical and electronic technology, basis of machining technology and NC machining technology, management of basic computer and enterprise;

(3) Be able to draw, calculate, test, retrieval document and operate basic process, and be good at the application of computer and foreign language;

(4) Professional knowledge necessary in a certain field, understand the frontier and trend of the subject development;

(5) Be able to scientific research preliminary, organize, manage and develop scientific technology;

(6) Strong self-learning ability, practical ability, innovative consciousness, unity and cooperation spirit and high comprehensive quality.

\section{CURRICULUM SYSTEM CONSTRUCTION}

According to the specialty training plan, five course platforms were established: general-common courses platform, basic course platform, professional course platform and practical course platform and quality development platform (curricular innovation practice), of which the structure is shown in figure 2.

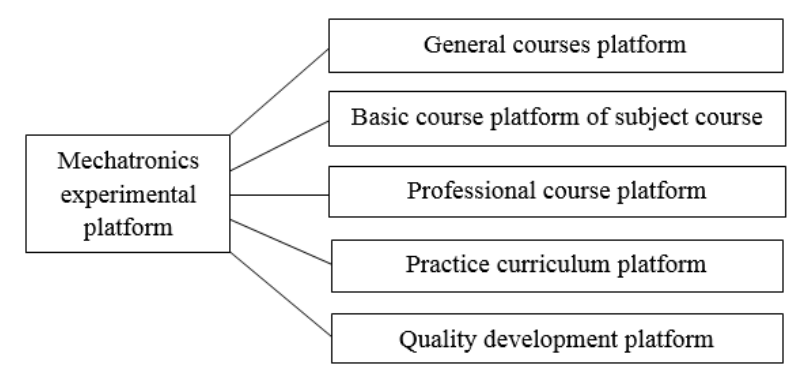

Fig. 2 Mechatronics Curriculum platform

Make the engineering case reference, engineering practice and scientific research integrate organically and make the classroom teaching more effectively by combining with the engineering practice of classroom teaching, heuristic teaching, inquiry, discussion, participatory teaching and inquiry learning, guide the students to participate in learning, to explore the effective way for teachers' scientific research and engineering practice integration in teaching. In order to achieve the purpose of training high-quality applied talents, the teaching system consists of experiment course, course design and graduation design mainly and the practice teaching system in extracurricular activities of science and technology innovation and scientific research and experiment auxiliary was constructed, and design comprehensive and designed experiment reasonably, course design, graduation design and practical teaching content of innovative experiment projects of the undergraduates', which creates the time characteristics of training of engineering ability. The main features of mechanical and electrical integration laboratory are: the main experimental teaching equipment is composed and developed by teachers and students, and the experimental guidance textbooks are also written by them independently according to teaching rules and requirements. Establish the experimental class regard the students as the center, realize the teaching mode consists of students mainly and teachers' guiding auxiliary for the laboratory according to the level of cognition and knowledge of students. Carry out open experimental teaching mode: the students are allowed to design, do experiments, analysis and innovation in the laboratory for 24 hours. Increase the content of comprehensive and innovative experiments, cultivate students' innovative consciousness.

\section{A. Self-developing key experimental instruments}

There are no relevant products or very expensive prices for some instruments and equipment that is needed in the teaching for electromechanical laboratory. For example, commonly used electronic chips generally require $+3.3 \mathrm{~V}$ or $+5 \mathrm{~V}$ regulated power supply, commonly used sensors generally require $+15 \mathrm{~V}$ regulated power supply, and common operational amplifiers require $5 \mathrm{~V},+10 \mathrm{~V}$ or $+15 \mathrm{~V}$ high precision regulated power supply, the respective purchase of these equipment costs a lot. At the same time, in order to ensure the quality of the experimental teaching, teachers are not only supposed to be familiar with the theoretical knowledge of relevant courses, but also be familiar with the relevant experimental instruments and the composition of the experimental equipment. The implementation of key 
experimental instruments will not only make the instructor understand the experimental equipment composition principle to a further step, master the use of experimental instruments, guide students to carry out the experiment better, but also save the laboratory construction funds a lot, reduce the expenditure of experimental instruments. In the period of graduation design, teachers are allowed to guide students to complete the development of some experimental equipment, which is not only one more supplement for the experimental instruments and equipment, but also helps improve the quality of graduation design.

\section{B. Carry out open-experimental teaching}

The open experimental teaching method is able to change the teaching model from teacher laboratory to student oriented teaching mode. In the open experiment, students are allowed to choose the experiment content and the experiment time independently, which fully arouses the enthusiasm of the students. The less attention the teachers pay to the students' independent experiments, the more beneficial for the students to do the scientific research independently.

\section{Increase the content of comprehensive and innovative experiment}

Refresh experiment contents, increase the comprehensive and innovative, help students to conduct a comprehensive knowledge, train intelligence and skills of students in the core of cultivating students' quality of scientific experiment and thinking experimental design practical ability. Guide and encourage students to carry out creation, and guide students to participate in the machinery innovation competition, mechanical engineering training contest, undergraduates' science and technology innovation and skills competitions, national and provincial and municipal schools at all levels of competitions actively.

\section{Refresh experimental teaching means and constructing second-classroom}

Attempt the construction of "independent experiment" if the experimental teaching is fully open. The teaching method of combining teacher guidance experiment with students' independent experiment is put forward to meet the needs of different courses and provide conditions for the improvement of students' independent practical ability. The independent experiment also provides the "second classroom" for the students who want to do deep research on the experiment, the students are allowed to choose the experimental content according to correlation degree of the major in their spare time, or carry out their own experimental subjects. The laboratory is fully open in the experimental time, experimental content, equipment and other aspects. The experimental procedure is mainly based on the students' self-design, and the experiment is completed independently under the guidance of the advisers. These experiments include small inventions of science and technology, or even small scientific research projects. Encourage the students to apply the achievements with practical value for invention patent and utility model patent.

\section{CONCRETE SOLUTIONS}

\section{A. Carry out teaching reform and teaching methods deeply}

In order to improve the quality of teaching and the teaching level of teachers, it is supposed to carry out the research on teaching reform and teaching methods, strengthen the understanding of the teaching rules and curriculum construction, and continue to implement and improve the combination of the "lesson", "lectures" and "demonstration class". Organize the teacher to exchange teaching experience, feedback teaching information, guide and manage the students' learning activities.

\section{B. Improve the structure of teaching staff and the overall quality of teachers}

Establish talent competition mechanism to improve and optimize the teachers' educational structure, title structure, age structure, subject structure through the introduction, cultivation and distributing, build a group of teachers with excellent quality, optimized structure, meets the needs of undergraduate education, and is full of vigor and vitality.

\section{Strengthen the echelon construction of disciplines, train professional leaders, young-aged and middle-aged backbone teachers}

Introduce leaders of urgently-needed, key and characteristic professionals; Select and train leaders, youngaged and middle-aged backbone teachers with academic attainments, achievement in the construction of discipline major and strict academic style actively; Encourage young teachers to participate in short-term training, $\mathrm{Ph} . \mathrm{D}$. or master degree, select the outstanding young teachers to study abroad, to create conditions for the growth of young teachers.

\section{Strengthen the construction of "double qualified teachers" and improve teachers' practical teaching ability}

Formulate and implement specific measures of training plan of the quality of "double qualified teacher" and improve teachers' practical teaching ability, to make the teachers based on laboratory and training bases, by encouraging teachers to participate in the occupation qualification training and occupation qualification examination, social practice at the first line of production and construction, hire part-time teachers from large-scale enterprises and departments, to improve the quality of the "double qualified teacher", improve teachers' social practice ability and professional skills, which lays the foundation for the cultivation of applied innovative talents. 


\section{E. Carry out the evaluation for the teachers by undergraduates in an all-round way}

In order to improve teaching methods, teaching quality and teaching level of the teachers, a comprehensive evaluation of teaching activities and lectures by peer teachers and students is supposed to be carried out. The undergraduates' evaluation for teachers is a comprehensive evaluation for the teachers in the end of courses, which consists of the teaching methods, content, teachers' ethics and other aspects. In order to ensure the authenticity and validity of the evaluation, all students are required to participate in the courses, and the average value is taken as a comprehensive evaluation of teachers. The teaching leaders will talk with the teachers with poor evaluation or lower scores, and the professional teaches will attend lectures and examinations of them, in order to improve the overall teaching quality. The audit and evaluation by peer teachers require the teachers to attend lectures regularly by the relevant professional teachers, and discuss them. At the same time, every teacher is required to attend 1 peer lecture each semester at least, department director and professional leaders are supposed to attend 3 leadership lectures at least, and fill in the leader and the peer evaluation sheet of the course quality of their institute; In order to ensure the authenticity, every teacher is required to register at the Office of Institute Management for record and reference.

\section{CONCLUSIONS}

Through the implementation of the construction plan, the training system of innovative talents in the direction of electro-mechanical was constructed, which achieved the requirements of the times, and the purpose of high-quality applied mechanical talents with all-round development of morality, wisdom, body and beauty, a solid foundation, outstanding professional skills, high comprehensive quality, strong spirit of innovation and practice international vision, which meet the needs of local economic construction and social development for the talents.

\section{REFERENCES}

[1] Yang Zhe. On the development direction of Mechatronics in China: [J] urban construction theory research: electronic version, 2015 (2): 64-66. (In Chinese)

[2] Han Jing. Discussion on the teaching method of "mechanical drawing" the reform of $[\mathrm{J}]$. science and Technology Economic Herald, 2016 (33). (In Chinese)

[3] Wang Yao, high fortitude. Talking about the importance of learning mechanical basic course, [J]. read the world, 2016 (19). (In Chinese)

[4] Li Tianjing, Ben Nengjun, Chen Anzhu, et al. Mechatronics curriculum design teaching reform [J]. science journal, 2015 (9): 105-106. (In Chinese)

[5] Mao Hongmei. Discussion on practice teaching reform of Mechatronics Technology Specialty in Higher Vocational Education [J]. science and technology wind, 2014 (17): 200-200. (In Chinese)

[6] Xu Zuohua, school enterprise cooperation, construction of project-based professional curriculum system -- Taking Mechatronics major as an example, [J]. Vocational Education Forum, 2015 (30): 80-82. (In Chinese) 